\title{
Preparation and tensile properties of guar gum hydrogel films
}

\author{
Daniel Jussen, Sandeep Sharma, James K. Carson*, Kim L. Pickering \\ School of Engineering, University of Waikato, Private Bag 3105, Hamilton 3240, \\ New Zealand \\ *corresponding author: james.carson@waikato.ac.nz, Tel: +64 7838 4206, Fax: +648384835
}

\begin{abstract}
Guar gum hydrogels may be dried to form polymer films which have the potential for use as bio-degradable alternatives to polymers such as low density polyethylene. In this study, the tensile strength and tensile modulus of guar gel films having moisture contents ranging between 15 and $18 \%$ (wet basis) were measured at a strain rate of 1 $\mathrm{mm} / \mathrm{min}$. Mean tensile strengths of the films ranged between 25 and $40 \mathrm{MPa}$ (dependent on composition) which is of similar magnitude to the tensile strength data for polyethylene and cellophane that are reported in the literature. The mean tensile modulus of the films (1.5 to $2.5 \mathrm{GPa}$ ) was higher than the tensile modulus values reported for low density polyethylene but comparable to those for cellophane (3 GPa).
\end{abstract}

Keywords: guar gel films, bio-degradable polymers, tensile properties

\section{Introduction}

The significant environmental impact of plastic material refuse has triggered research into the development of plastics that degrade rapidly, leading to, in some cases, complete mineralization or bio-assimilation of the material ${ }^{1}$. Despite recent advances in this area, however, many large urban areas still suffer extensively from packaging litter since much of the material does not bio-degrade rapidly.

Guar gum is obtained from the ground endosperm of the guar legume (cyamopsis tetragonolobus) ${ }^{2}$, and has a range of uses in the food, cosmetics and pharmaceuticals industries ${ }^{2-8}$. The galactomannan chains of guar gum are also amenable to copolymerisation, e.g. by grafting with vinyl acetate-ethylacrylate ${ }^{9}$ or methyl-methacrylate ${ }^{10}$. While it is most commonly used as a binder or thickener, the addition of a cross-linker can produce stable hydrogels under suitable conditions ${ }^{4,6,11-16}$. The resulting gel may then be dried to produce clear 'plastic' films (Figure 1), which bio-degrade rapidly upon rehydration ${ }^{6,17}$. As such, guar hydrogel films offer a sustainable alternative to petroleum-derived polymers (e.g. polyethylene) for products such as shopping bags and packaging films. Alternatively, the films could be used as food coatings. 
A number of studies have been performed investigating the mechanical properties of guar gum (or a derivative) mixed with other polymeric materials. Xiao et al. ${ }^{18}$ measured the tensile strength of films produced from blends of chitosan and hydroxypropyl guar gum. They found that the maximum tensile strength (59 MPa) occurred with a $60 \%$ guar gum blend. Rao et al. ${ }^{19}$ also measured tensile properties of guar gel/chitosan mixtures, although it appears there may have been some error in reporting their data, since the tensile strength values in their Figure 2 varied between 4 and $12 \mathrm{kPa}$ (when it would be expected that the data would be in the region of MPa). Huang et al. ${ }^{20}$ measured the tensile strength of films prepared from cationic guar gel mixed with poly acrylic acid and measured a maximum tensile strength of $41 \mathrm{MPa}$, at a composition of $50 \%$ guar gel. Shenoy and D'Melo ${ }^{21}$ measured the tensile strength of films prepared from blends of acrylated guar gum and acrylic emulsion and reported tensile strengths varying between 0.5 and $3 \mathrm{MPa}$. Mikkonen et al. ${ }^{22}$ measured the tensile strength of films formed from guar gum plasticized with glycerol or sorbitol, and found that the maximum tensile strength (13 MPa) was obtained with $20 \%$ glycerol. Das et al. ${ }^{23}$ modified the chemical structure of guar to make the film water resistant and biocidal. They reported tensile breaking points of $21.95 \mathrm{MPa}$. Saberi et al. ${ }^{24}$ prepared edible biofilms based on guar gum and pea starch with a variety of plasticisers and reported a maximum tensile strength of 34.1 MPa. They observed that the addition of plasticisers tended to decrease tensile strength ${ }^{25}$. Strand et al. ${ }^{26}$ investigated the use of spray-on cationic guar-gum biofilms made with $50 \%$ sorbitol for use as paper coatings. They reported a relatively low tensile strength of $18 \mathrm{MPa}$, probably due to the presence of the sorbitol plasticizer.

Polymer blends are considered advantageous since their physical properties may be tailored (within practical limits) to a given application ${ }^{18}$. However, there is no reason why guar gum could not be used on its own which would remove the need for the blending stage of an industrial scale production. There does not appear to be any data in the literature for the tensile properties of films based solely on guar gum as the polymeric material. The aim of this work was to measure the tensile properties of guar gel films in order to assess whether they would be sufficient for use as packaging material.

\section{Guar gel film preparation method}

\subsection{Guar gum}

Since guar gum is a natural product, its molecular structure is highly dependent on the climate, the planting season and other environmental parameters ${ }^{4}$. It is therefore impossible to characterize guar gum as a specifically defined molecule or polymer, but only as a mixture of carbohydrates which share a general structure. Eighty per cent by mass of food grade guar gum powder is comprised of the galactomannan guaran which consists of a $(1 \rightarrow 4)$-beta- 
mannopyranosyl backbone with $(1 \rightarrow 6)$ linked alpha-D-galactopyranosyl side chains ${ }^{14}$. The remainder of commercial guar gum is comprised of other carbohydrates such as, for example, glucose and arabinose as well as protein impurities. The molecular weight of guar gum is normally between $220 \mathrm{kD}$ and $250 \mathrm{kD}$ and the molar ratio of galactose to mannose is typically between $1.5: 1$ and $1.8: 1^{25}$. The chemical structure of the guaran repeat unit is shown in Figure 2. All films used in this study were prepared using food-grade guar gum obtained from Danisco (Grindsted ${ }^{\mathrm{TM}}$ Guar 250).

\subsection{Mixing}

The solution and gelling characteristics of guar gum are sensitive to a variety of factors including time (both mixing and setting), temperature, concentration, $\mathrm{pH}$, powder particle size and the type of cross-linker used ${ }^{4,5,27}$. The guar powder is extremely hygroscopic which requires either a very slow rate of addition to the solvent (impractical other than at small scale) or high-shear mixing, which has a significant influence on the temperature and viscosity of the solution; factors which in turn influence the gel-forming characteristics ${ }^{28}$. High-shear mixing can break polymer chains, which is not desirable for gelation ${ }^{29}$ and produces a significant quantity of heat. Centrifugation is a potential alternative to high shear mixing; however, it may be prohibitively expensive on an industrial scale.

The dissolved guar gum forms a viscous, non-Newtonian fluid with thixotropic behaviour, due to the entanglement of the galactomannan chains ${ }^{4}$. The viscosity is dependent on the concentration of guar gum in the solvent, mixing time and the solvent $\mathrm{pH}^{28}$. Jussen ${ }^{4}$ measured the viscosities of guar gel solutions as functions of time (at $40{ }^{\circ} \mathrm{C}$ ) in acidic, neutral and basic solutions in order to determine the optimum mixing time, shear rate and solvent $\mathrm{pH}$ and concluded the following:

- To maintain polymer chain length, guar gum gels should be mixed for as short a time as possible. For $10 \mathrm{~g}$ $\mathrm{L}^{-1}$ solutions the minimum mixing time was approximately 10 min (at $8000 \mathrm{rpm}$ ).

- In order to increase the guar powder loading (and hence reduce the drying load), acidic solvents should be used. Of the solvents considered, $1 \mathrm{M} \mathrm{HCl}$ was the most effective solvent at reducing the solution viscosity.

- Acidic solutions produced more ductile films than alkaline or neutral solutions

In this study all guar gel film samples used for tensile testing were prepared by mixing at $8000 \mathrm{rpm}$ for 10 minutes in $1 \mathrm{M} \mathrm{HCl}$ solution. Three concentrations of guar powder were used: $10 \mathrm{~g} \mathrm{~L}^{-1}, 12 \mathrm{~g} \mathrm{~L}^{-1}$ and $15 \mathrm{~g} \mathrm{~L}^{-1}$.

\subsection{Setting}


It is important that the mixing process does not proceed too long since air bubbles become entrained in the solution as the gel starts to set (the greater the guar gum content of the solution the greater the susceptibility to air entrainment). The gels were spread out on a smooth surface to dry as soon as possible after the guar gum powder had fully dissolved. A Perspex grader was drawn over the gel once it had been poured onto the drying surface to ensure uniform thickness of the gel and resultant film.

\subsection{Drying}

To prevent brittleness and cracking, the gels were dried at relatively low temperature $\left(<60^{\circ} \mathrm{C}\right)$. The drying needed to occur at a sufficient rate to prevent the growth of microbial organisms typically present within bulk feedstocks of the guar gum powder. In these experiments the gels were dried by small (10 mm diameter) fans at near ambient temperature.

\section{Moisture content of guar gel films}

Since mechanical properties depend on the composition of the films, the moisture content of the films was determined by drying the films at $100{ }^{\circ} \mathrm{C}$ until the mass of the sample had reached an equilibrium value. The wetbasis moisture content was determined from Eq. (1):

$$
W=\frac{m_{i}-m_{f}}{m_{i}} \times 100 \%
$$

Where: $W$ is the wet-basis moisture content, $m_{i}$ is the initial mass of the guar gel film, $m_{f}$ is the final mass of the film. Figure 3 shows the moisture content of the films as a function of the guar concentration in the initial gel. Each point represents the average of five film moisture content measurements. As expected the moisture content of the film decreases as the concentration of guar gum in the initial gel increases.

The guar gels have a wet-basis moisture content of approximately $99 \%$, while the films have wet-basis moisture contents of less than $20 \%$. This means that 90 to $100 \mathrm{~g}$ of water must be evaporated per gram of film produced, which represents a substantial drying load. However, because the gels were spread out in a thin layer (5 $\mathrm{mm}$ or less) drying rates were high even at ambient temperature, provided forced convection was employed.

\section{Tensile strength tests}

The tensile strength (failure stress) and tensile modulus (Young's modulus) of the guar gum films were measured using an Instron 33R4204 machine at a strain rate of $1 \mathrm{~mm} / \mathrm{min}$. For each of the three gel concentrations 
five film samples were prepared and five strips from each film were cut into samples $160 \mathrm{~mm}$ length and $15 \mathrm{~mm}$ width (25 test specimens for each gel concentration). The gauge length of the samples was $124 \mathrm{~mm}$. The thickness of the specimens was measured using a micrometer at three different positions along the film length, and typical values were of the order of $0.05 \mathrm{~mm}$.

A typical tensile test plot (stress vs. elongation) is shown in Figure 4. Stress was consistently observed to initially increase slowly up to a plateau after which it increased more rapidly with respect to strain, although the gradient decreased slightly before final fracture. The consistency of this trend suggests that it represents structural mechanisms and implies some type of yielding occurring at lower stresses, possibly due to the failure of a particular type of intermolecular bond. Overall, behaviour was generally brittle; there was no obvious macroscopic yielding and failure occurred at strains between 0.015 and 0.025 (Figure 5).

The mean tensile strengths for each gel concentration are shown in Figure 6 (the error bars correspond to the standard deviation in the results). The tensile strength increased as the concentration of guar gum in the hydrogel increased from approximately $25 \mathrm{MPa} 10 \mathrm{~g} \mathrm{~L}^{-1}$ to $40 \mathrm{MPa}$ at $12 \mathrm{~g} \mathrm{~L}^{-1}$; however, the tensile strength decreased from $12 \mathrm{~g} \mathrm{~L}^{-1}$ to $30 \mathrm{MPa}$ at $15 \mathrm{~g} \mathrm{~L}^{-1}$. The increase in strength between $10 \mathrm{~g} \mathrm{~L}^{-1}$ and $12 \mathrm{~g} \mathrm{~L}^{-1}$ may be attributed to the fact that an increase in the solids composition of the gels (and hence the films) allowed for a greater number of crosslinks between polymer chains. The decrease in strength between the $12 \mathrm{~g} \mathrm{~L}^{-1}$ gels and $15 \mathrm{~g} \mathrm{~L}^{-1}$ gels may be attributed to the greater number of bubbles that were unavoidably entrained (Figure 7) during the preparation of these gels, as a result of the increase in viscosity that accompanied the increase in guar gum concentration ${ }^{27}$. The bubbles would have caused stress concentrations and reduced the cross-sectional area of the test samples, which would explain the reduction in tensile strength.

The tensile modulus was calculated from the second linear portion of the stress-strain curve (Figure 4), rather than the initial linear portion, which often was not as well defined, perhaps due do extension or 'straightening' of the samples rather than due to strain. Generally the calculation was based on the change in strain between stresses of $10 \mathrm{MPa}$ and $20 \mathrm{MPa}$, although in some cases the sample failed below $20 \mathrm{MPa}$, in which case other criteria were used. The tensile modulus (Figure 8) appeared to decrease as the gel composition was increased from $10 \mathrm{~g} \mathrm{~L}^{-1}$ to 12 $\mathrm{g} \mathrm{L}^{-1}$, although there was no apparent decrease in elastic modulus from $12 \mathrm{~g} \mathrm{~L}^{-1}$ to $15 \mathrm{~g} \mathrm{~L}^{-1}$. It is difficult to draw conclusive inferences about trends in the tensile modulus data since the standard deviation in the results (which was used to plot the error bars in Figure 7) was high; however, the lack of change between gel composition of $12 \mathrm{~g} \mathrm{~L}^{-1}$ and $15 \mathrm{~g} \mathrm{~L}^{-1}$ could again probably be attributed to the influence of the large number of bubbles in the films made from the $15 \mathrm{~g} \mathrm{~L}^{-1}$ gels (Figure 7c). 
The tensile strength of the guar gel films was of similar magnitude to the tensile strength of polyethylene (e.g. $20 \mathrm{MPa}^{30}$ ) and cellophane (35- $\left.75 \mathrm{MPa}^{31}\right)$. It is also similar in magnitude to tensile strengths of the blended polymer film data referred to above ${ }^{18-22}$, and demonstrates that guar gum itself is capable of providing sufficient tensile strength for packaging purposes. The guar gel films were 3 to 5 times stiffer than low density polyethylene (tensile modulus $\left.590 \mathrm{MPa}^{30}\right)$, but similar to cellophane $\left(3 \mathrm{GPa}^{31}\right)$.

More work is required to in order to optimise the preparation of gels with $15 \mathrm{~g} \mathrm{~L}^{-1}$ guar gum concentration without the entrainment of so many bubbles, and subsequently to determine whether tensile strengths higher than 40 MPa might be achieved.

\section{Conclusion}

Tensile testing was performed on films prepared by drying guar gum hydrogels. The moisture content of the films varied between 15 and $18 \%$ (wet basis). The tensile strength of the films initially increased with increasing guar content, but subsequently decreased as the guar content continued to increase (this decrease was attributed to weakening of the films by air bubbles entrained in the films). The scatter in the tensile modulus was high and it was therefore difficult to draw conclusions about the dependence of tensile modulus on composition. The tensile strength was of similar magnitude to the tensile strength values for low density polyethylene and cellophane that are reported in the literature, while the tensile modulus was higher than polyethylene and slightly lower than cellophane.

\section{References}

1. Avella, M, De Vlieger, JJ, Errico, ME, Fischer, S, Vacca, P, Volpe, M. Biodegradable starch/clay nanocomposite films for food packaging applications Food Chem. 2005; 93(3): 467-474

2. Kirk-Othmer, Encyclopedia of Chemical Technology, Vol. 12, John Wiley \& Sons, New York, (1994)

3. Carson, JK, Lovatt, SJ, Tanner, DJ, Cleland, AC. Experimental measurements of the effective thermal conductivity of a pseudo-porous food analogue over a range of porosities and mean pore sizes J. Food Eng. 2004; 63(1): 87-95

4. Jussen, D., Postgraduate Research Report, University of Waikato, 2008

5. Sandolo, C, Matriacardi, P, Alhaique, F, Coviello, T. Effect of temperature and cross-linking density on rheology of chemical cross-linked guar gum at the gel point. Food Hydrocolloids 2009; 23(1): 210-220

6. Thombare, N., Jha, U., Mishra S., Siddiqui, M. Z. Guar gum as a promising starting material for diverse applications: A review. Int. J. Biol. Macromol. 2016; 88: 361-372 
7. Racic, A, Calija, B, Milic, J, Milasinovic, N, Krajisnik, D. Development of polysaccharide-based muco-adhesive ophthalmic lubricating vehicles: The effect of different polymers on physicochemical properties and functionality, J. Drug Delivery Sci. Tech. 2019; 49: 50-57.

8. Singh, S, Singh, G, Arya, SK. Mannans: An overview of properties and application in food products. Int. J. Bio. Macromolecules 2018; 119:79-95.

9. Singh, V, Singh, A, Joshi, S, Malviya, T. Grafting of vinyl acetate-ethylacrylate binary monomer mixture onto guar gum. Int. J. Biol. Macromol. 2016; 84: 442-447.

10. Singh, V, Tiwari, A, Shukla, P, Singh, SP, Sanghi, R. Grafting of methylmethacrylate on to the plant seed galactomannans using potassium presulphaste/ascorbic acid redox pair. Reactive Functional Polym. 2006; 66(11): 1306-1318

11. Gliko-Kabir, I, Yagen, B, Penhasi, A, Rubinstein, A. Phosphated crosslinked guar for colon-specific drug delivery: I. Preparation and physicochemical characterization. J. Controlled Release 2000; 63: 121-127

12. Wang Q, Ellis PR, Ross-Murphy SB. The stability of guar gum in an aqueous system under acidic conditions. Food Hydrocolloids, 2000; 14(2): 129-134

13. Wang Q, Ellis PR, Ross-Murphy SB. Dissolution kinetics of guar gum powders. I. Methods for commercial polydisperse samples. Carbohydr. Polym. 2002; 49(2): 131-137

14. Wang Q, Ellis PR, Ross-Murphy SB. Dissolution kinetics of guar gum powders-II. Effects of concentration and molecular weight. Carbohydr. Polym. 2002; 53(1): 75-83

15. Wang Q, Ellis PR, Ross-Murphy SB. Dissolution kinetics of guar gum powders-III. Effect of particle size. Carbohydr. Polym. 2006; 64(2): 239-246

16. Wang Q, Ellis PR, Ross-Murphy SB. Dissolution kinetics of water-soluble polymers: The guar gum paradigm. Carbohydr. Polym. 2008; 74(3): 519-526,

17. Kaith, B. S., Sharma, R. Kalia, S., Guar gum based biodegradable, antibacterial and electrically conductive hydrogels, Int. J. Biol. Macromol. 2015; 75: 266-275

18. Xiao, C., Zhang, J., Zhang, Z., Zhang, L. Study of blend films from chitosan and hydroxypropyl guar gum, J. Appl. Polym. Sci. 2003; 90: 1991-1995

19. Rao, MS, Kanatt, SR, Chawla, SP, Sharma, A. Chitosan and guar gum composite films: Preparation, physical, mechanical and antimicrobial properties. Carbohydr. Polym. 2010; 82(4): 1243-1247

20. Huang, Y, Lu, J, Xiao, C. Thermal and mechanical properties of cationic guar gum/poly(acrylic acid) hydrogel membranes. Polym. Degrad. Stab. 2007; 92(6): 1072-1081 
21. Shenoy, MA, D’Melo, DJ. Effect of modified galactomannan on acrylic film properties. Pigment Resin Technology 2008; 37(5): 284-290

22. Mikkonen, KS. Rita, H, Helen, H, Talja, RA, Hyvonen, L, Tenkanen, M. Effect of Polysaccharide Structure on Mechanical and Thermal Properties of Galactomannan-Based Films. Biomacromolecules, 2007; 8(10): 31983205

23. Das, D, Ara, T, Dutta, S, Mukherjee, A. New water resistant biomaterial biocide film based on guar gum. Bioresour. Technol. 2011; 102(10): 5878-5883

24. Saberi, B., Thakur, R, Bhuyan, DJ, Scarlett, CJ, Stathopoulos, CE. Development of edible blend films with good mechanical and barrier properties from pea starch and guar gum. Starch/Staerke 2017; 69(1-2) 1600227

25. Saberi, B., Chockchaisawasdee, S., Golding, JB, Scarlett, CJ, Stathopoulos, CE. Physical and mechanical properties of a new edible film made of pea starch and guar gum as affected by glycols, sugars and polyols, Int. J. Biol. Macromol. 2017; 104: 345-359

26. Strand, A, Kouko, J, Oksanen, A, Salminen, K, Ketola, A, Retulainen E, Sundberg, A. Enhanced strength and elongation potential of paper by spray addition of polysaccharides. Cellulose 2019; 26(5): 3473-3487.

27. USEPA, Pesticides and Food: What the Pesticide Residue Limits are on Food, Electronic Code of Federal Regulations (e-CFR)

28. Nand, S, Proshanta, G. Modelling the effect of guar gum on physical, optical, barrier and mechanical properties of potato starch based composite film, Carbohydr. Polym. 2018; 200: 498-507.

29. Robinson G, Ross Murphy, SB, Morris ER. Viscosity, molecular weight relationships, intrinsic chain flexibility, and dynamic solution properties of guar galactomannan, Carbohydr. Res., 1982; 107: 17-32

30. Ashby, MF., Jones, DRH. Engineering Materials 1: An Introduction to Properties, Applications and Design, $3^{\text {rd }}$ ed., Oxford, Butterworth Heinemann, 2005

31. Mark, H. F., Films and Sheeting, Encyclopedia of Polymer Science and Technology, Wiley, 1968, pp786 - 787 


\section{Figure Captions:}

Figure 1: Guar-gel film prepared as described in Section 2, and used in tensile testing

Figure 2: Chemical structure of guaran (guar gum repeat unit) (source: Wikimedia Commons, public domain).

Figure 3: Moisture content of films versus guar concentration of gels.

Figure 4: Typical stress versus extension plot for guar gel films

Figure 5: Mean failure strains for guar gel films

Figure 6: Mean tensile strength at yield values for guar gel films

Figure 7: Bubble entrainment in guar gel films a) $10 \mathrm{~g} \mathrm{~L}^{-1}$, b) $12 \mathrm{~g} \mathrm{~L}^{-1}$ c) $15 \mathrm{~g} \mathrm{~L}^{-1}$

Figure 8: Mean tensile modulus values for guar gel films 


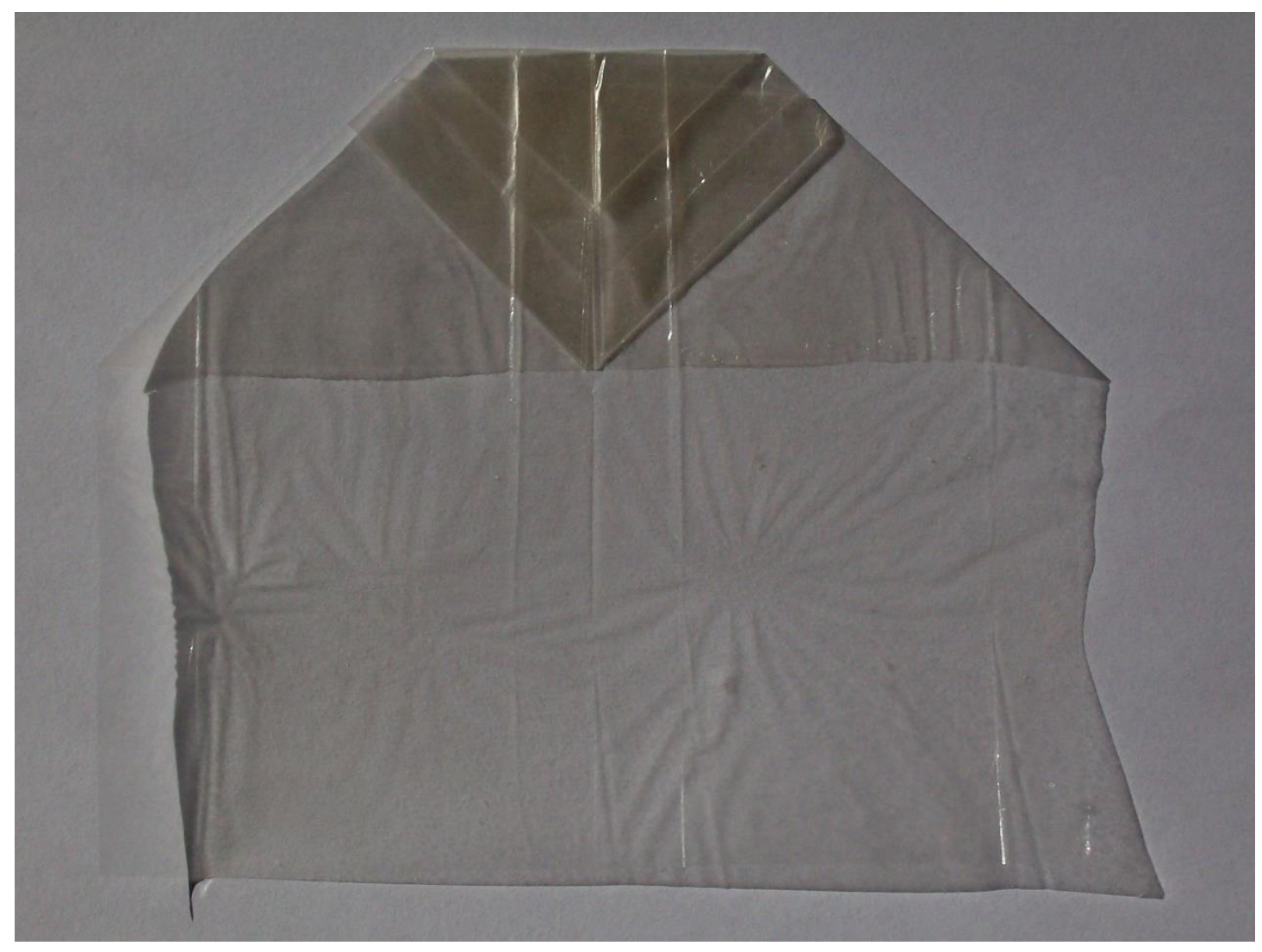

Figure 1: 


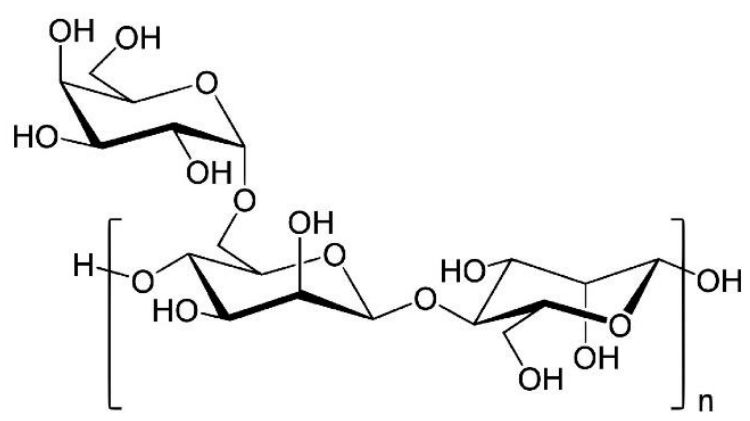

Figure 2: 


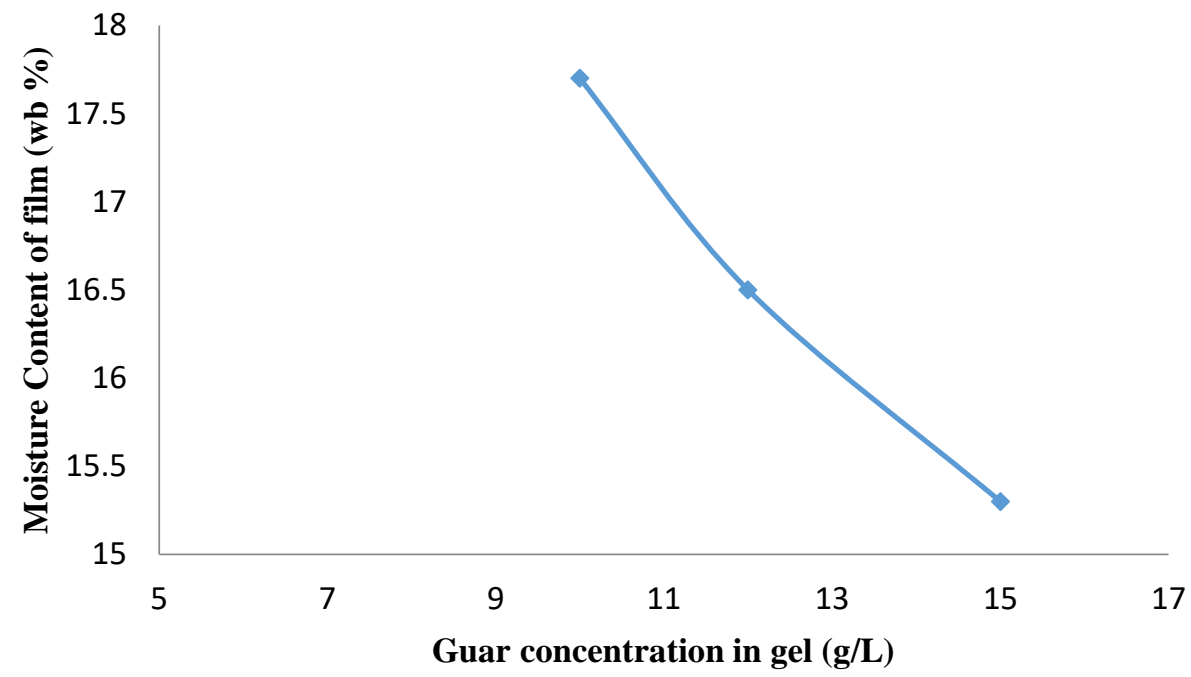

Figure 3: 


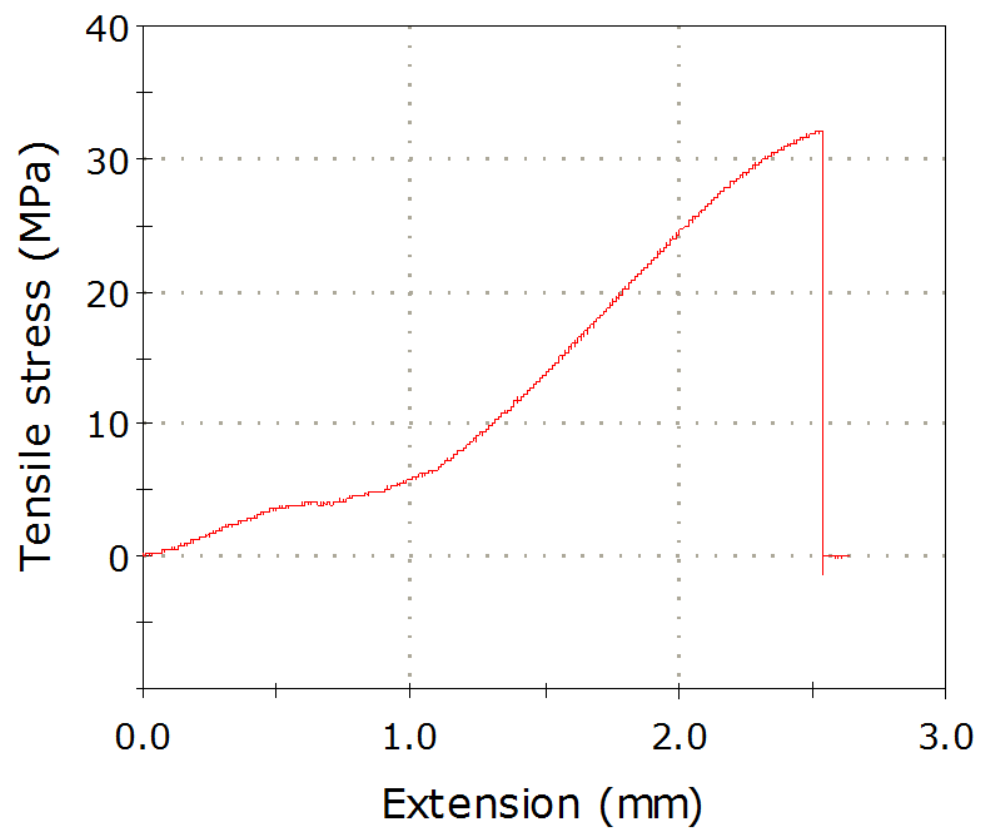

Figure 4: 


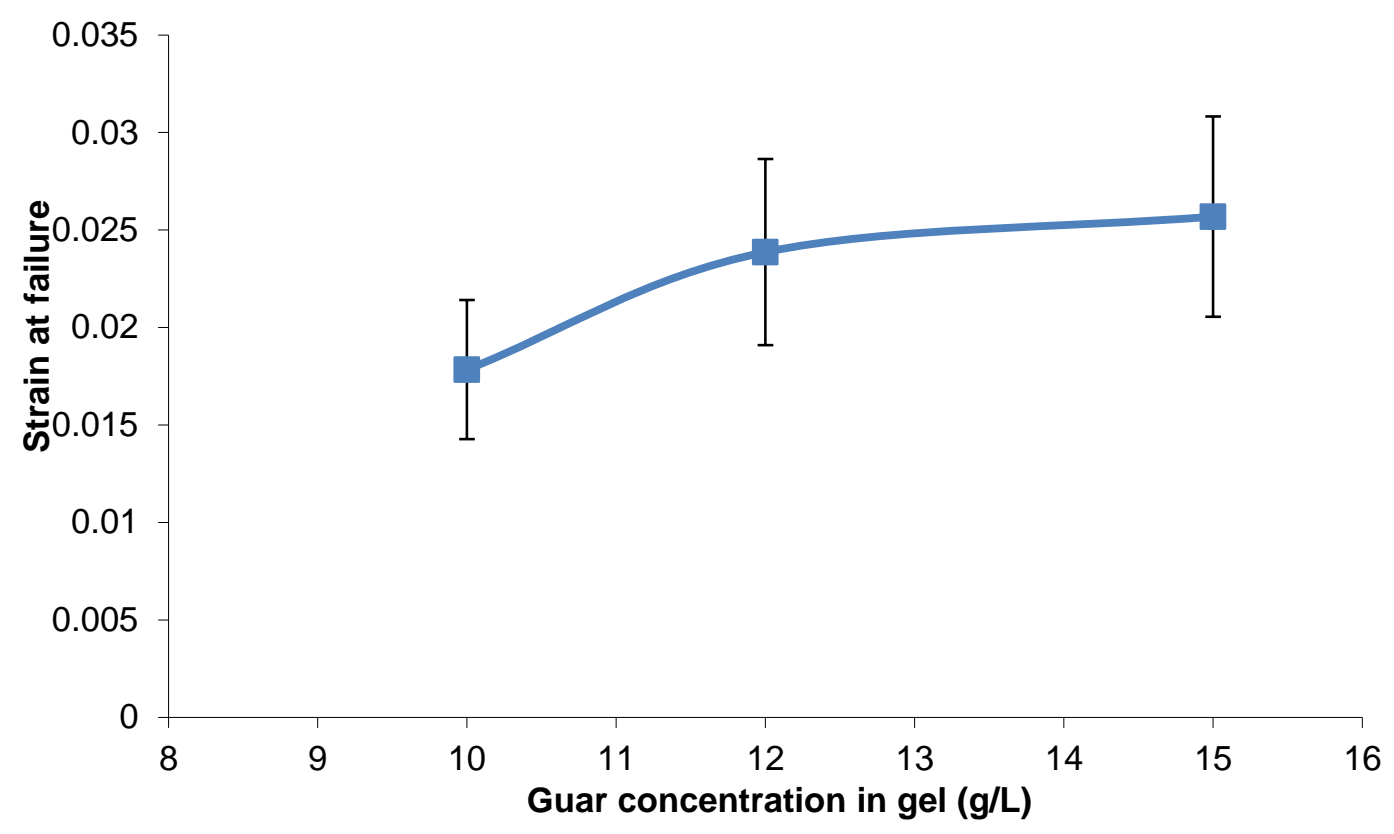

Figure 5 


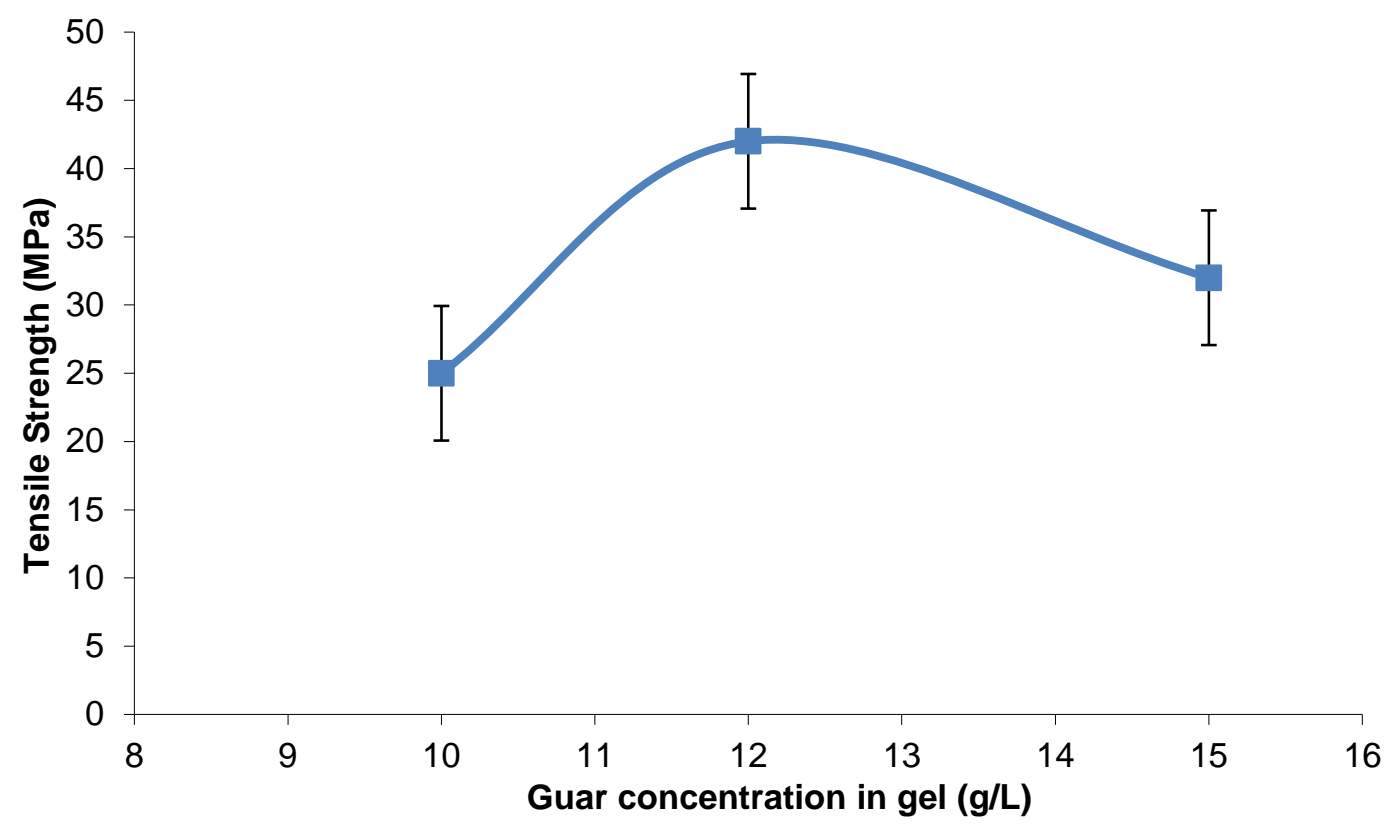

Figure 6: 


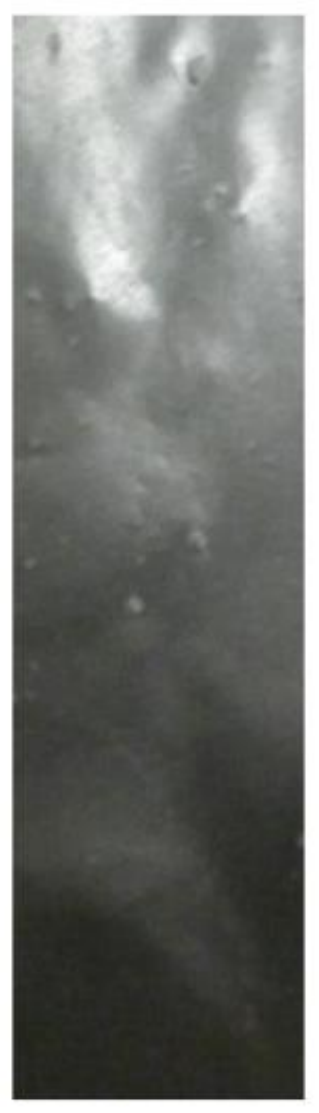

a)

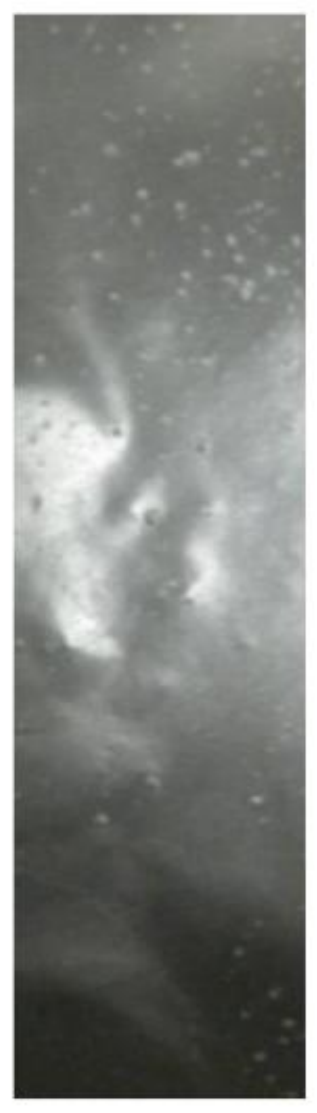

b)

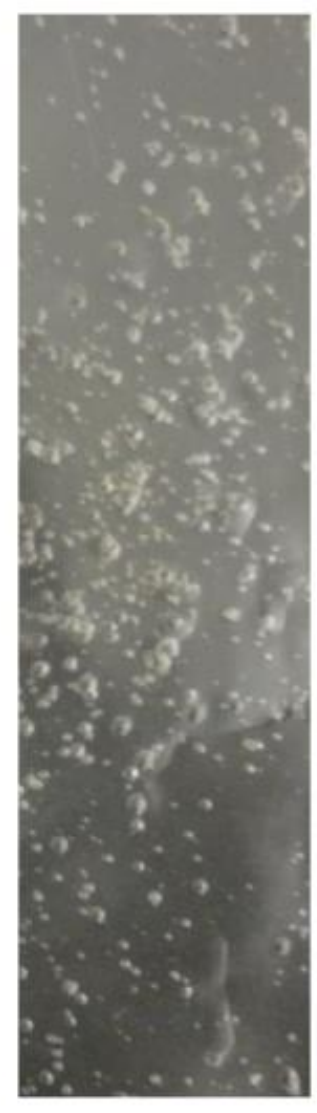

c)

Figure 7: 


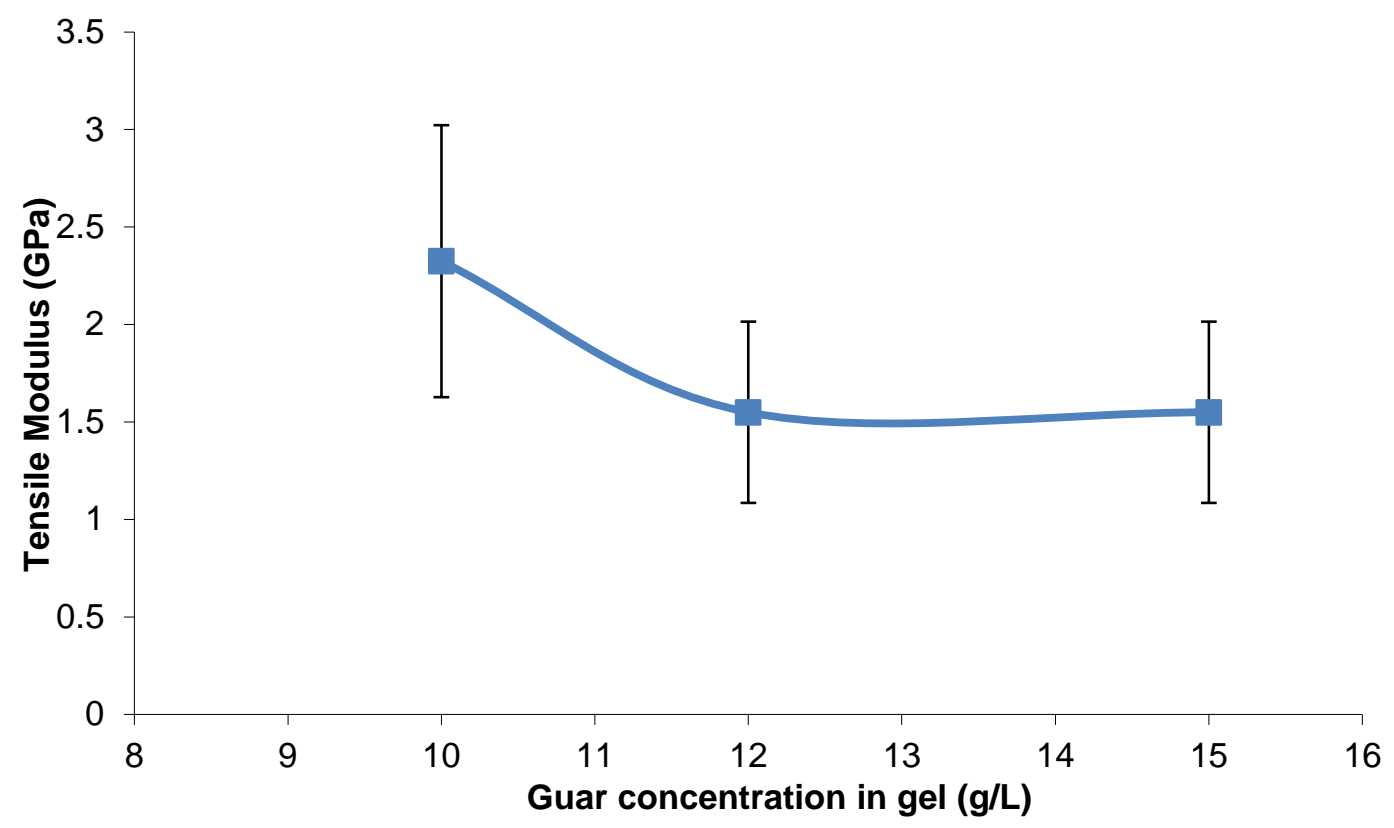

Figure 8 